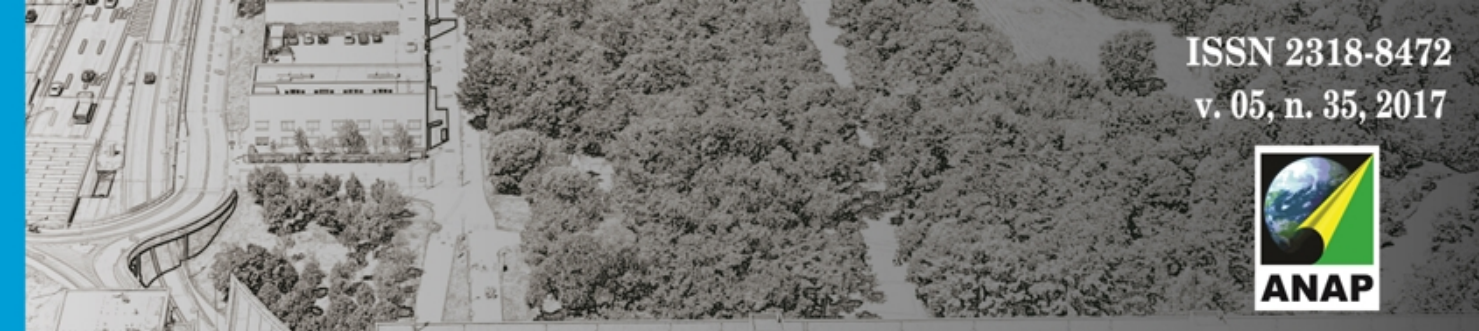

Gerenciamento de Cidades

National Journal of Cities Management

\title{
Qualidade das Gestões Municipais: Ensaio sobre uma Metodologia de Análise
}

\author{
Quality of Municipal Management: \\ Test on an Analysis Methodology
}

Calidad de las Gestiones Municipales:

Ensayo sobre una Metodología de Análisis

Barbara Puccinelli Perrone

Programa de Pós-Graduação em Arquitetura, Tecnologia e Cidade, Faculdade de Engenharia Civil, Arquitetura e Urbanismo, Universidade Estadual de Campinas - UNICAMP

barbarapperrone@outlook.com

Lauro Luiz Francisco Filho

Programa de Pós-Graduação em Arquitetura, Tecnologia e Cidade, Faculdade de Engenharia Civil, Arquitetura e Urbanismo, Universidade Estadual de Campinas - UNICAMP

laurolffilho@gmail.com 



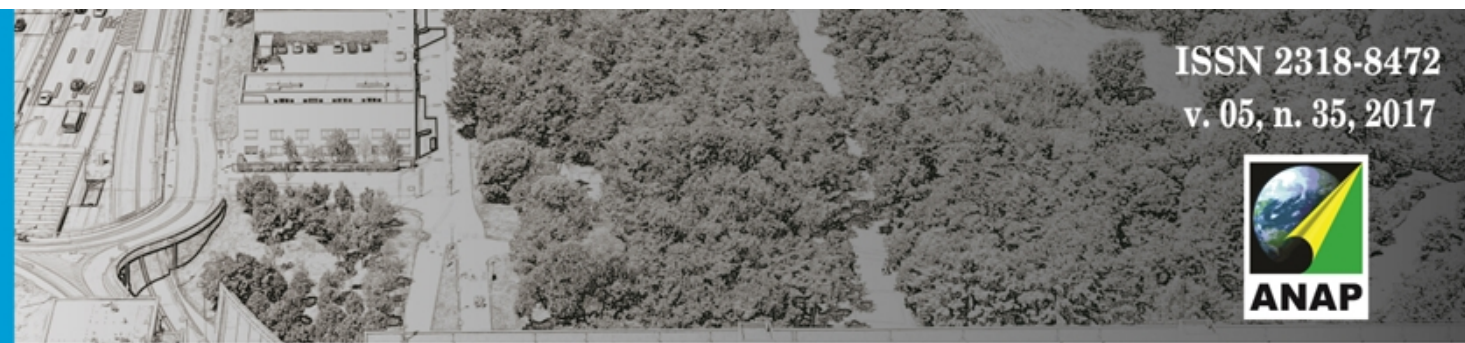

\section{INTRODUÇÃO}

A herança política perpetuada desde os tempos da Coroa Portuguesa, continuada pelas leis que ora instituíam ora barravam a autonomia local, favorecendo alguns e não outros se tornaram parte da cultura nacional geral refletida hoje numa incapacidade administrativa dos municípios, onde leis de favorecimentos e interesses particulares continuam prevalecendo dentro do quadro geral que governa as cidades.

Dessa forma, a população se mostra insatisfeita com a situação política nacional, colocando os gestores municipais em situação de reprovação. Contudo, é preciso avaliar, através de dados concretos, o que realmente foi realizado ou não, priorizado ou não, frente à demanda social das cidades.

Considera-se como base a definição de Correa (1989, p. 11), a qual discorre sobre os agentes formadores do solo urbano, caracterizando o grupo social excluído como a grande massa da população, o governo na figura do gestor municipal e seu partido político, além dos três outros grupos que se alternam em ações conjuntas e que impactam diretamente no uso do solo, ou seja, nas políticas públicas. São eles: grandes donos de terras, proprietários das grandes indústrias e, por fim, os especuladores imobiliários.

Em municípios com número maior de habitantes, existem outros agentes sociais que interferem na composição e na disputa de forças da formação do solo urbano. Em contrapartida, em municípios com menor número de habitantes, os cinco agentes se mostram mais definidos, atuantes e identificáveis na sociedade.

Determina-se, portanto, a hipótese de que em municípios com população de até 50.000 habitantes, de menor porte, o agente dominante pode estar centralizado no gestor da cidade, o prefeito. Ainda, este agente pode ser um acumulador de funções, exercendo a atividade de agente imobiliário, proprietário de terra ou dono de indústria. E, caso tal hipótese seja confirmada, a gestão do município onde tal fenômeno ocorre pode estar sendo conduzida por interesses que fogem do coletivo.

\section{OBJETIVO}

Sendo assim, a proposição do artigo é discutir o processo de formação dos municípios, abordando todo o processo de configuração política, indissociando da formação da sociedade, estando esta sob a ótica da formação espacial. Ainda, discute-se uma metodologia de análise comparativa entre as gestões municipais, a fim de identificar falhas e acertos em medidas e ações realizadas dentro do município e mensurar dados aparentemente imensuráveis. Esta análise comparativa se faz sobre os deveres municipais relacionados à saúde, educação, economia e uso do solo. E, considerando a política como a expressão vívida das classes sociais e suas disputas, bem como da democracia na discussão de implantação ou não das medidas e 


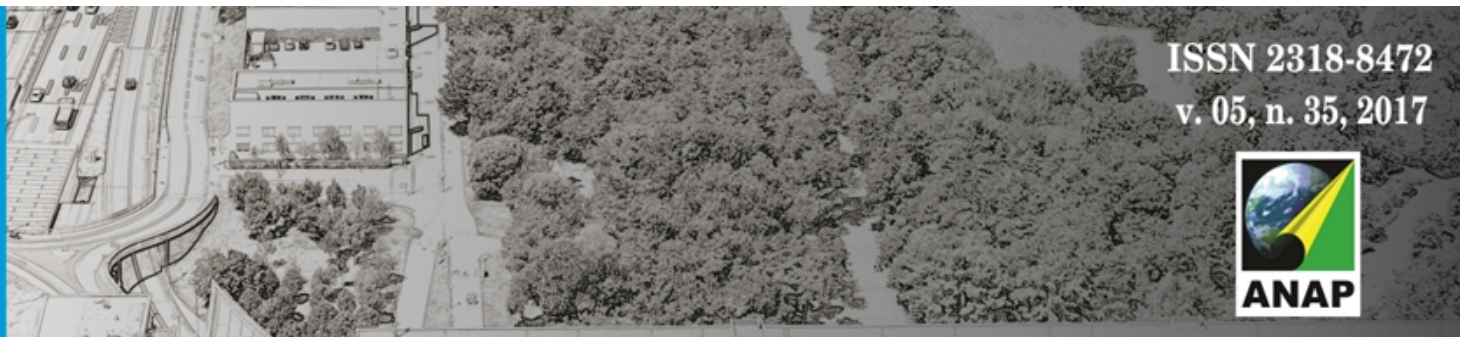

Revista Nacional de

ações comunitárias, é através da alternância de sua configuração que se estrutura a presente discussão.

Entende-se que a temática aqui abordada se mostra assunto de interesse comum, interdisciplinar e servindo aos pesquisadores, políticos, civis e planejadores, pois visa compreender a formação dos municípios num todo, desde a formação antropológica da sociedade quanto sua consolidação espacial. Ainda, a porcentagem de municípios considerados de pequeno porte, no Brasil, gira em torno de $84 \%$ (IBGE). Por isso, existe a necessidade de estudar e compreender a formação e gestão desse grupo que perfaz quase todo o território nacional.

\section{REVISÃO DA LITERATURA - BREVE CONTEXTUALIZAÇÃO HISTÓRICA}

Segundo Corrêa (1989, p.7), o espaço urbano é definido como o conjunto de diferentes usos da terra que, lado a lado caracterizam a cidade. Através de todos os usos que fazem a cidade, são definidos os centros, locais de aglomeração, áreas destinadas às residências, aos comércios, bem como indústrias e também expansão. Ou seja, os usos definem o próprio valor da terra. Contudo, é de se considerar que, ainda que tais atividades sejam distintas, pelo fato de estarem justapostas, mantêm um diálogo que se dá através dos fluxos de veículos e pessoas, que diariamente migram de um canto para outro da cidade, buscando trabalho, lazer, moradia, serviço público e, consequentemente criam esse diálogo intra-espacial. Porém, existe outra forma de relacionar tais fragmentos da cidade, que não os espaciais. São as relações que envolvem capital, investimento e poder, ou seja, relações sociais.

O que o autor afirma, portanto, é que tais relações sociais acabam refletidas no espaço urbano. Ou seja, a formação da sociedade reflete na forma física da cidade.

O espaço da cidade é assim, e também, o cenário e o objeto das lutas sociais, pois estas visam, afinal de contas, o direito à cidade, à cidadania plena e igual para todos. (CORREA, 1989, p.9).

Ainda segundo Corrêa (1989, p.11), existe um conjunto de agentes que determinam os usos dos espaços através de suas relações sociais, ou seja, produzem o espaço urbano. São os chamados agentes sociais: I. Proprietários dos meios de produção, destacando-se os grandes industriais; II. Os proprietários das terras; III. Promotores/especuladores imobiliários; IV. Estado, que dentro da sociedade municipal está incorporado na Prefeitura e na figura do Prefeito; V. grupos sociais excluídos, ou seja, a grande maioria que, na segregação social e urbana, se vê à parte das tomadas de decisões e do direito à própria cidade em que habitam.

Segundo Engels (1941, p. 155), o surgimento do Estado se deu como uma necessidade de moderar o conflito existente entre as classes que compõem a sociedade capitalista e seus interesses contrários. Com isso, o surgimento desse poder visava mantê-los dentro dos limites 


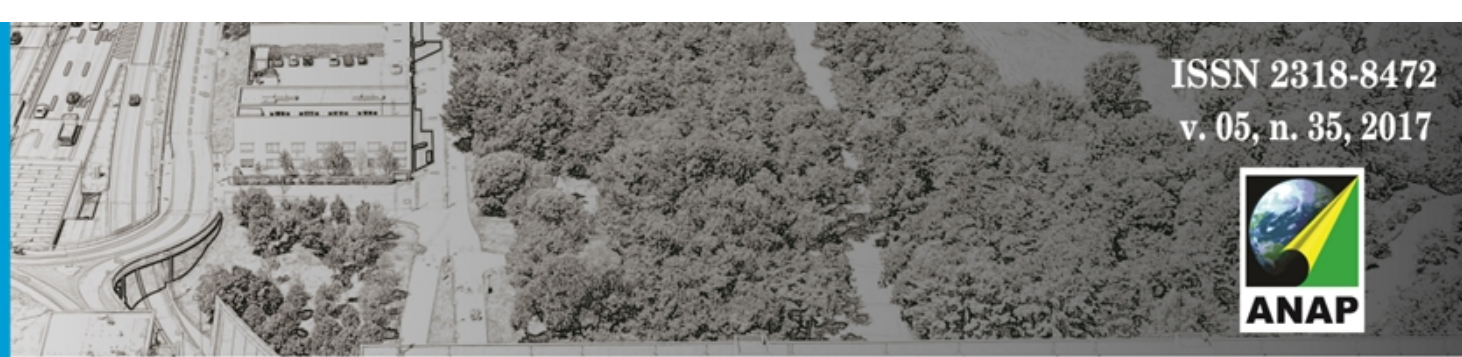

Gerenciamento de Cidades

da "ordem", ou seja, da lei. Porém, adotando um caráter independente em relação aos conflitos e as classes sociais, o mesmo passa a deter um poder de dominação desses grupos, afinal, como já dito, seu status o tornava superior enquanto mediador.

Ainda, conforme Harvey (2005, p.79), o Estado sempre esteve presente enquanto agente central da sociedade capitalista, porém, moldando-se sempre de acordo com o amadurecimento desta e suas necessidades.

Através das afirmações expostas acima, tem-se que, um órgão que se fez necessário de sua instituição, com a finalidade de mediar as lutas e os conflitos de interesses, os quais distorciam o interesse comum buscando induzir o mesmo para os seus próprios interesses, se mostrou como mais um agente na briga pelo poder, podendo, por consequência de sua posição superior na sociedade, dominar os demais agentes, mediando de maneira tendenciosa os conflitos existentes, de acordo com seus interesses.

Ainda, o fato da Constituição de 1988 ter conquistado a descentralização de poder do Estado e denotado maior e representativa autonomia aos municípios, favoreceu para que essas circunstâncias sociais viessem novamente à tona.

\subsection{ANÁLISE POLÍTICA ATRAVÉS DA FORMAÇÃO DA SOCIEDADE}

Durante todo o processo de formação do município brasileiro, ora este possuía autonomia, ora tal habilidade the era retirada. Considerando as alternâncias de todo esse percurso, desde o período de colonização, houve predominância de uma classe, um grupo sobre o outro. Como exaltado, isto teve início com a Corte Portuguesa que comandava os portugueses enviados ao Brasil. Estes, por sua vez, comandavam os senhores, e, na sequência, os escravos eram dominados. Ou seja, em todos os períodos históricos, existiu uma influência que vinha desde o colonizador, seguida pelo seu parentesco ou relação mais próxima, o conterrâneo neste caso, depois dos produtores donos das terras e por fim, os servos.

Segundo Silva (2015, p.7), na literatura que discorre sobre o tema, é possível encontrar duas grandes linhas de abordagem: a primeira, chamada de Teoria das Elites, e a segunda, com a ideia de Classe Politicamente Dominante. O que pode ser constatado é que, em ambas as vertentes são reconhecidas a existência de dois grandes grupos no cenário político das sociedades, sendo um o dominante e outro o dominado dentro da esfera política. Ou ainda, conforme explana Gaetano Mosca:

Em todas as sociedades - desde as parcamente desenvolvidas, que mal atingiram os primórdios da civilização, até as mais avançadas e poderosas - aparecem duas classes de pessoas: uma classe que dirige e outra que é dirigida (MOSCA, 1966, p. 51). 


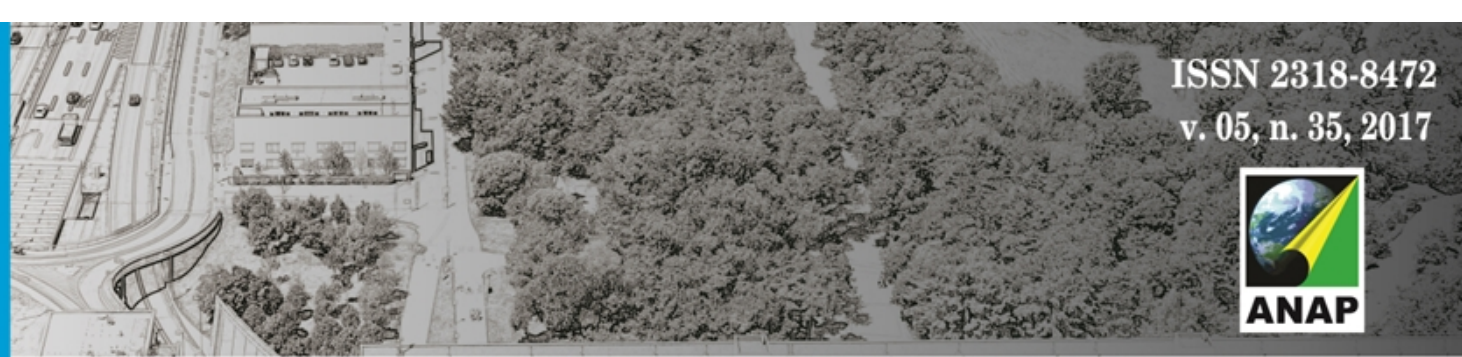

Gerenciamento de Cidades

Seguindo o pensamento de Mosca, o grupo que domina, por ser em menor número, consegue uma organização melhor e por isso consegue a dominação da outra. Trazendo para a realidade dos municípios aqui tratados, o mecanismo pode ser comparado: cidades menores, menos coligações político-partidárias e, portanto, melhor e mais fácil articulação das existentes, para organizar e atingir/ceder, através do apoio tramitado sob a pressão dos dominados, que exigem compensações como troca de favores com a classe dirigente para que se mantenham então no poder.

Ainda, considerando a continuação do pensamento do referido autor, de que os membros de tal classe possuem dominância intelectual e qualidades que lhe conferem superioridade sobre a classe inferior, existe aí novo gancho para relacionar com o histórico político das cidades foco desta pesquisa: a herança moral destes atributos faz com que, muitas vezes, uma mesma família influente em determinada cidade, se alterne no poder com outra família influente desse mesmo local. Ainda, em muitas vezes, essas famílias que possuem moral elevada e dominância de status perante as demais, também é detentora de poder econômico superior, também herdado de seus antecessores, criando dessa forma, um ciclo de poder, seja econômico, intelectual ou político. E, como acontece nesse determinado processo, não há espaço para que outros grupos entrem na disputa, fortalecendo ainda mais a dominância.

Riqueza, família ou contatos sociais também ajudam em muitas outras ocasiões a conseguir o rótulo de elite em geral, ou da elite governante em particular, para pessoas que de outra maneira não poderiam ter acesso sobre eles (PARETO,1966, p. 74).

Partindo para tal abordagem, se faz retomar o conceito de Corrupção, inserido agora no âmbito político. Para Ferreira Filho (2001, p. 218), a corrupção depende do padrão moral do indivíduo e das coletividades distintas. Assim, pressupõe-se uma correlação entre nível geral de moralidade da população e também dos políticos.

A partir dessa ideia, entende-se o porquê da não efetividade em controlar ou sanar a corrupção com a criação das leis federais que regem o assunto. O problema, por assim denominar, da corrupção, transcende o limite de aplicar ou não lei específica para inibir, controlar ou evitar a corrupção. Assim, a pergunta que deve ser feita é: aquele que cria tal legislação, em sua consciência moral, estaria disposto a aplica-la? Porque, como já percebido em outros âmbitos, muitas leis são criadas na sociedade brasileira, porém poucas são aplicadas.

Ao analisar na literatura dos autores supracitados acima, Mosca e Pareto, é possível encontrar probabilidade de circulação, alternância dos governantes, contudo, todos dentro de uma mesma classe moral, a elite. Nesse pensamento, pode-se entender que, de fato, com a renovação de uma mesma minoria na detenção do poder, a grande massa nunca estará representada, resultando então nessa segregação social atual, retratada pela segregação 


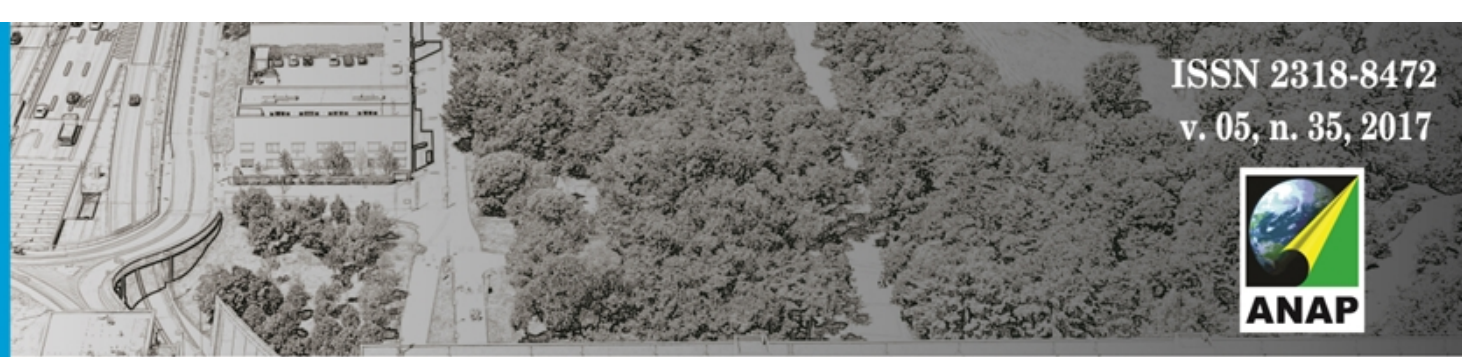

Gerenciamento de Cidades

espacial nas cidades, como forma de explicitar essa diferença de interesses particulares de uma classe para outra.

Segundo Rezende (2011, p.22), os municípios de pequeno porte ainda reproduzem características de gestão patrimonialista apesar das inúmeras reformas administrativas ocorridas nos governos estaduais e federal, se fazendo perpetuar o nepotismo, personalismo, clientelismo e troca de favores.

Além de Rezende, Bacelar (2011, p.6), também parte da mesma afirmativa dizendo que quanto à administração das pequenas cidades, esta ainda não rompeu ainda com as práticas patrimonialistas e ainda adicionam que a mesma é entendida pelos agentes políticos como uma extensão familiar, como se o bem público pertencesse aos bens familiares particulares. Para tal, cita Holanda (2004, p.146), com sua também afirmação quanto ao homem brasileiro ou "homem cordial". Nesse sentido, é uma forma de indistinção entre o ambiente público e privado, administrando então a cidade como este administra sua família.

Os concursos arranjados, a doação de material de construção, o aviamento constante de receitas médicas, a doação de combustível para parte da população, o pagamento de viagens a pessoas mais carentes, o emprego fácil e o nepotismo são práticas que não dependem do partido que está no poder, nem da "ideologia" reinante no momento. Depende, sim, de uma prática patrimonialista herdada de um modo, de um estilo, de uma herança ibérica ainda arraigada, em que o controle social sobre o poder público ainda é pífio (BACELAR, 2011, p. 6).

Através dessa afirmação, é possível corroborar os dados quanto à continuidade de famílias ou partidos frente ao poder local, onde em cidades consideradas pequenas, com nomes famílias influentes presentes na fala cotidiana dos munícipes, através de referências na denominação das ruas e avenidas principais, parques, bairros, monumentos e da própria cidade, todas elas formam a elite apontada por Mosca e Pareto.

Considera-se, portanto, na sociedade atual, a possibilidade de a figura de um civil ou de uma família ou de um único partido político desempenhar o papel de um destes, o gestor local. E, obviamente isso reflete em impactos na própria gestão e desenvolvimento do município.

\subsection{A CONQUISTA DA AUTONOMIA POLÍTICA MUNICIPAL COM A CONSTITUIÇÃO DE 1988}

Segundo Maricato (2011, p.151), o processo brasileiro de urbanização, ocorreu de forma a não superar algumas características do período colonial e imperial, se fazendo repetir a concentração de terra, renda e poder, exercício esse da política do favor e da aplicação parcial da lei. Através de tal afirmação, a hipótese de favorecimento particular frente ao coletivo, toma 


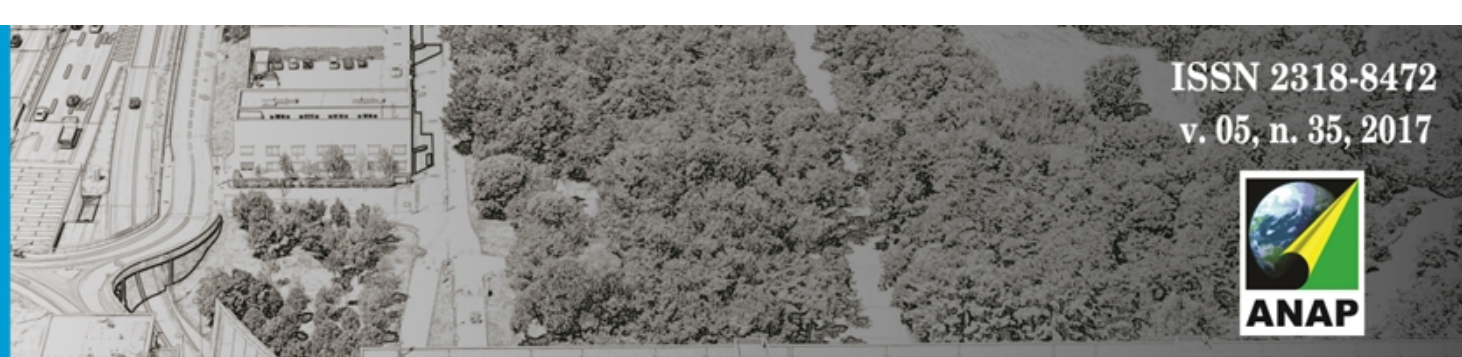

Gerenciamento de Cidades

fundamento ao se analisar comparativamente as diferentes realidades brasileiras durante todo o seu processo de colonização e monarquia até os dias atuais. E, ainda, perceber similaridades principalmente quanto às suas negligências e aplicação arbitrária dos mecanismos de regulação, os quais, teoricamente, deveriam servir e ouvir a todos.

Previamente, para que possa ser pensada como negligente a situação atual na legislação brasileira, é preciso compreender o termo corrupção, do qual muitos têm citado, porém sem entender, de fato, sua real tradução:

O termo corrupção surgiu a partir do latim corruptus, que de forma abrangente significa decompor, deteriorar algo. Por tanto, é atribuída ao corruptor à habilidade de degradar ou perverter aquilo que, em regra, deveria ser decente (MARTINEZ, SANTOS, 2015 p. 16).

Ainda que tal processo de corrupção tenha surgido desde antes de Cristo, conforme Martinez (2015), através da afirmação de que no século IV a.C., o filósofo Aristóteles de Estagira, já denominava o ato de corrupção como uma alteração do conteúdo, corrompendo assim a ética do homem, no Brasil, ela chega com a descoberta e a colonização.

Segundo Fernandes (1972, p.), a forma como ocorreu a colonização brasileira, pelos portugueses, pode ser considerada rígida, manifestada principalmente pelos interesses sociais, econômicos e políticos ocultando os empreendimentos que inseriam a Coroa, como a intenção dos negociantes urbanos em projetos de expansão ultramarina e estamento dos nobres. Por isso, a característica primeira dessa colónia que estava sendo formada, era de "exploração", a qual seguia o modelo de ordem social de Portugal, privilegiando sempre como pretendido, a Coroa.

A partir dessas duas considerações, temos que realidade social-política refletida hoje na sociedade brasileira, desde sua formação inicial, já mostrava traços de favorecimento induzido, interesses particulares e divisão de classes.

Essa relação entre colônia e metrópole, Coroa, pode ser percebida nos dias atuais no regime hierárquico de poder vertical no Brasil. Bastos $(1998$, p.155) destaca traços municipais primários, como por exemplo, a falta de autonomia do próprio município prevalecendo assim à dependência de um poder maior, o Estado. Isso aconteceu durante o Brasil-colônia, onde apesar de existir uma societária típica, os poderes dos próprios senhores, sendo estes nobres ou não, detinham o poder o qual a Coroa permitia, e não mais do que isso. Assim, percebeu-se a evolução da Coroa como um Estado absolutista.

Sendo assim, a formação do município no Brasil não pode ser considerada como clássica. Devese considerar que no período de colonização o surgimento do município brasileiro não se deu pela necessidade de resolução de problemas e conflitos gerados pela vida em sociedade. Neste caso surgiu unicamente por disposição da Coroa Portuguesa. 


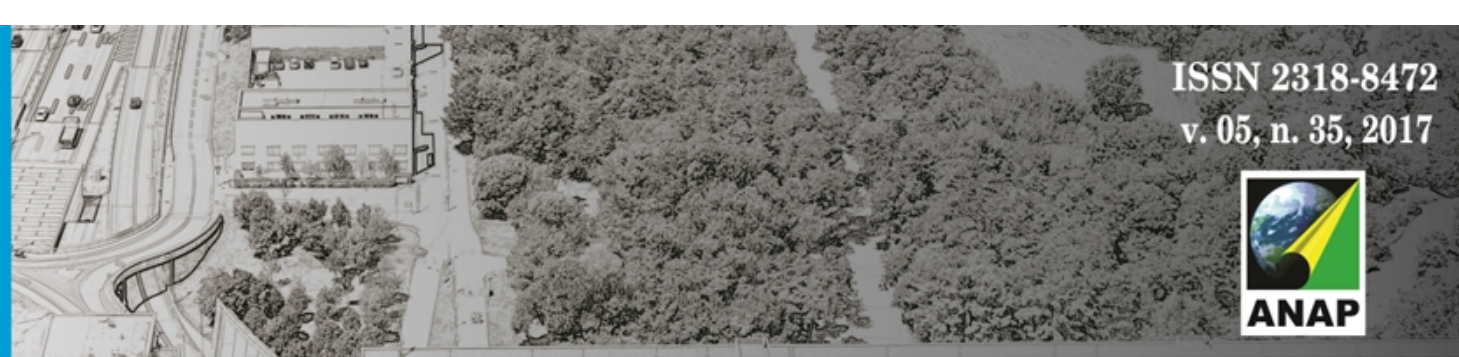

Gerenciamento de Cidades

As primeiras ordens que davam regimento aos municípios no Brasil seguiam as de Portugal. Portanto, as Ordenações Manuelinas (1532) e posteriormente, Ordenações Filipinas (1603), deveriam definir e reger esses novos locais. Através dessas ordenações, surgiram os "Concelhos" Municipais, supostamente órgãos de administração local que, na realidade, não representaram grande poder de decisão nos eventos da história política nacional, porém, mostraram enorme força e peso na política colonial através de conflitos vivenciados e relatados.

A decadência da autonomia municipal coincide com a descoberta e início da exploração das minas, entre os séculos XVII e XVIII. Ainda, Portugal havia perdido comércio com as Índias e, na África, apenas o comércio de escravos Ihe rendia lucro. Dessa forma, o Brasil foi visto como a única fonte alternativa a ser preservada e explorada pelo Reino. Assim, restrições passaram a serem impostas tanto sobre comércio quanto a produção gerada pela colônia, tomando o seu auge com a descoberta do ouro e diamante.

Com maior atuação da Coroa na Colônia, burgueses passaram a tomar o poder até então detido pelos produtores rurais, fazendo declinar o poder das câmaras e dar lugar novamente à autoridade da metrópole. Dessa forma, as autonomias municipais foram se esvaindo, centralizando o poder político, que se fortaleceu ainda mais com a vinda da Corte em 1808 e, posteriormente, com a instituição do Governo de Pedro I no Rio de Janeiro.

Em 1828, câmaras municipais passaram a corporações meramente administrativas, como peças da "engrenagem" monárquica, sendo submetidas ao controle exercido pelos Conselhos Gerais, Assembleias Provinciais e Governo Geral.

Portanto, durante a monarquia, foi vista uma organização política centralizada. Contudo, com a transformação das Províncias em Estados soberanos, começaram a aparecer os princípios básicos federalistas. Estes, por sua vez, trouxeram o enfraquecimento da União e dos municípios, atribuindo maior poder ao Estado. Porém, a Revolução ocorrida em 1930 modificou a organização política, pois visava aumentar o poder central. Contudo, conforme menciona Leal (1997, p.99), o interesse dos poderes dos Estados consistia mais em conseguir apoio e votos dos chefes políticos locais os quais conseguiam, em troca, carta-branca para atuar nos seus municípios.

Ou seja, a ordem administrativa ficava, na realidade, em segundo plano. Com a Constituição de 1934, foram asseguradas novamente algumas autonomias aos municípios, bem como aumento da renda municipal (determinados impostos e taxas). Todavia, órgãos de fiscalização dessas finanças também foram instituídos, ou seja, houve certa contradição nessa tal autonomia concedida.

Antes que os municípios se institucionalizassem dentro desse novo arranjo legal, um golpe de Estado, em 1937, fez com que uma nova Constituição substituísse a anterior, neste mesmo ano. Contrariando a Constituição de 1934, essa nova Constituição se caracterizava como antimunicipalista, reduzindo autonomia e renda municipal. Assim, as diretrizes do Governo Central subordinavam o Estado Novo e os municípios se tornaram depreciados. 


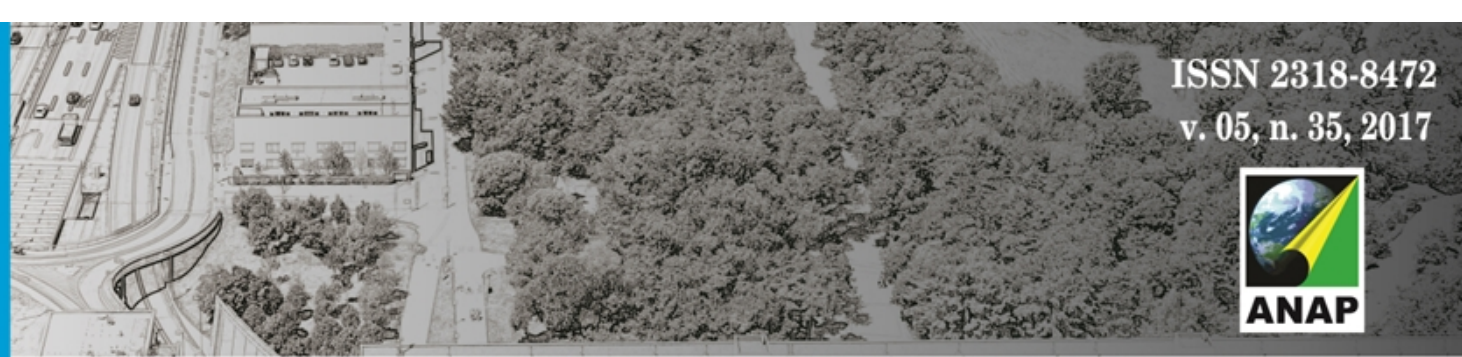

Gerenciamento de Cidades

Em 1946 foi instituída a Assembleia Constituinte e então, restaurada a autonomia municipal, dando ao município certa soberania ainda que sem o papel político ocorrido no primeiro período do Brasil-colônia.

Em 1964, a Revolução Armada "lança por terra" grande parte das conquistas municipais. A ditadura militar visava a centralização do poder e, consequentemente, enfraquecimento do poder local. Em 1969, uma emenda a qual fora considerada por muitos como uma nova Constituição frente à de 1937, abriu caminho para uma quase alcançada efetivação do município enquanto ente federativo. Contudo, com a instituição de algumas exigências fiscais, aumentouse o controle federal da aplicação dos recursos nos municípios.

Já com a Constituição de 1988, o município passa, de fato, a ser considerado como ente federativo, sendo reconhecida sua importância enquanto peça fundamental da organização político-administrativa brasileira.

Contextualizado o marco na história dos municípios, é preciso compreender o poder do governo local e da sociedade frente à nova política de gestão destes municípios.

\subsection{AS MUDANÇAS NA FORMA DE GOVERNAR, PÓS CONSTIUIÇÃO DE 1988}

Segundo Miranda (2009, p. 384), com o objetivo de minimizar as atividades do Estado central, os constituintes de 1988 trabalharam a Constituição em dois caminhos: a) atender às demandas dos movimentos sociais, sindicatos e partidos políticos, em um momento de transição política marcada pela abertura democrática e b) comprometer-se com os Estados e Municípios ao garantir aos mesmos a descentralização dos recursos provindos dos tributos, significando um aumento substancial de suas receitas.

Essa partilha de poder no qual o município se insere, sendo assegurada na Constituição, resulta então em sua autonomia. Segundo Santos (2005, p. 138), passa então a ser possível, na escala municipal, o reconhecimento das especificidades contidas no âmbito regional, trazendo uma base normativa, configurando uma área, caracterizada essencialmente como um território usado.

A atuação do governo municipal é o resultado da composição da aliança necessária à instituição desse governo. Suas possibilidades serão determinadas pela maneira como este se relacionará com um conjunto de determinações externas (mais fortes nas pequenas cidades), e também da conciliação da pressão que advém das demandas internas. O estudo da autonomia municipal significa, neste caso, a capacidade do município em interferir em seus próprios rumos, como também em favor de quem o faz, pois o faz dentro de um pressuposto da contradição capitaltrabalho.

\section{METODOLOGIA}




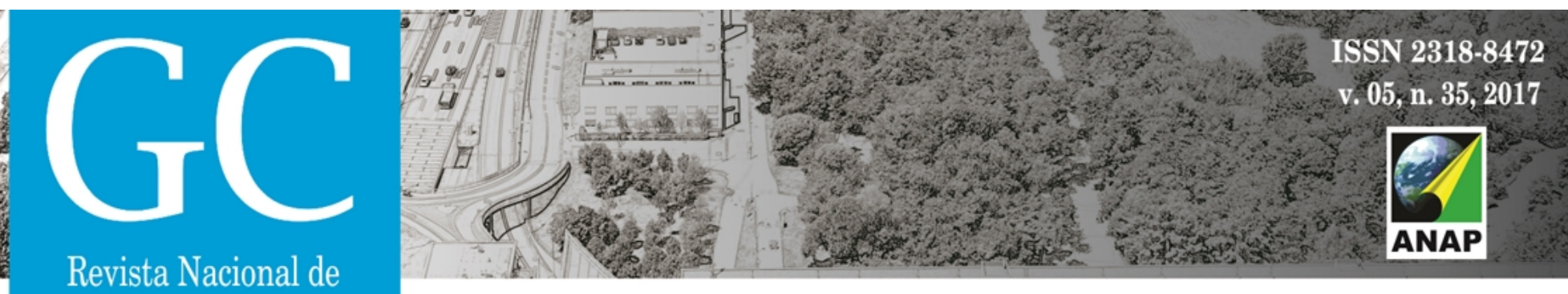

Depois de considerado o processo de formação municipal, bem como sua autonomia conquistada e, entendido os seus deveres e direitos enquanto ente federativo, se tornam conhecidos seus limites e poder de ação frente à sociedade que o perfaz.

Sendo assim, indicadores municipais que se referem à atenção básica à saúde, educação básica, sociedade, economia e uso do solo passam a pertencer também à esfera local, podendo então ser comparados.

Considerando a constituição de 1988 como o grande marco na história dos municípios brasileiros, pois, a partir dela, o município foi reconhecido como ente federativo, conquistando sua autonomia política através da instituição do Plano Diretor Municipal e também da regularização das eleições, onde os prefeitos passaram a ser eleitos em todo o território nacional, tal ano foi considerado e justificado como recorte temporal da análise, sendo o primeiro dos seis mandatos políticos a serem analisados: 1989 - 1992; 1993 - 1996; 1997 2000; 2001 - 2004; 2005 - 2008; 2009 - 2012.

Como forma de padronizar a coleta de dados dos mandatos, foi determinado o último ano de cada gestão para serem colhidas e analisadas as informações: 1992; 1996; 2000; 2004; 2008; 2012. Sendo o ano de 2017 como o ano de realização da pesquisa, os dados do mandato de 2013-2016 foram descartados por não estarem ainda contabilizados e regulamentado nos órgãos federais de pesquisa.

Através do exposto acima, procurou-se identificar a existência da gestão municipal continuada. Tal gestão se desdobrou em dois possíveis cenários: político-partidária, com variação do gestor, mas não do partido político e fisiológica/familiar.

\section{METODOLOGIA APLICADA - RESULTADOS}

Como o presente artigo foi extraído de uma pesquisa de pós-graduação que segue em andamento, serão apresentados dados recém-coletados, porém não finalizados, de maneira a exemplificar os indicadores verificados e embasar o entendimento da proposta de metodologia aqui exposta.

\subsection{UNIVERSO E GRUPO RECORTE}

Com a institucionalização da RMRP (Região Metropolitana de Ribeirão Preto) em 2016, o Estado de São Paulo passou a contar com um total de seis RM's (Regiões Metropolitanas). E, dessas seis regiões, a RMC é aquela que detém a segunda maior população, com pouco mais de três milhões, ficando atrás apenas da RMSP, a qual ultrapassa a marca de vinte e dois milhões de habitantes. Tal população se vê distribuída num território que, segundo o IBGE (2016) chega a $3.791 \mathrm{~km}^{2}$. Ainda, segundo o IBGE (2015), a RMC gera cerca de $8 \%$ do Produto Interno Bruto PIB, estadual. Tal dado é decorrente do fato de o destaque da RMC ser o parque industrial 


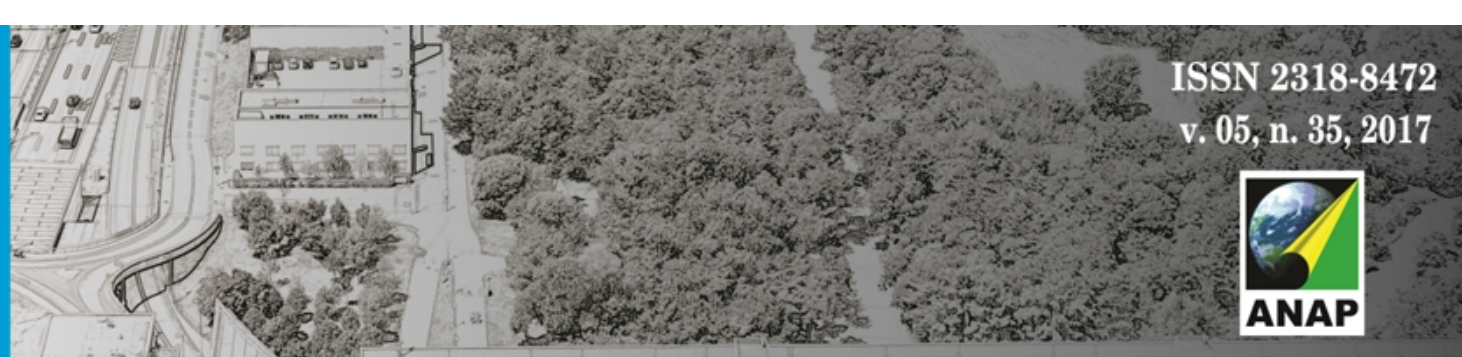

Gerenciamento de Cidades

diversificado, com produções distintas e complementares ao mesmo tempo. Além disso, conta com a presença de centros inovadores no campo das pesquisas científicas além do Aeroporto de Viracopos (segundo maior do país). A Região Metropolitana de Campinas se justifica pela conjunção de potencialidades econômicas advindas do dinamismo da própria aglomeração e pela dimensão das carências sociais.

A região é conhecida como uma área estratégica no mundo dos negócios (VITTE, 2007). Tais dados colocam a RMC como a décima maior Região Metropolitana do país, sendo que dentre as demais, é a única que não apresenta uma capital como a cidade-núcleo.

Segundo Nota Técnica de Estimativas da População dos Municípios Brasileiros com data de referência em 10 de julho de 2014, fornecida pelo IBGE, é possível calcula-se que $87 \%$ dos municípios brasileiros possuem número de habitantes igual ou inferior a 50.000. Na RMC, temos que $30 \%$ dos municípios se encaixam na classificação indicada acima. Os outros $70 \%$ dos municípios, variam entre 50.001, 100.000 e acima de 1.000 .000 de habitantes, sendo o último referente à cidade de Campinas.

O grupo de seis cidades da RMC que se encaixam no perfil-recorte é: Morungaba; Holambra; Engenheiro Coelho, Santo Antônio da Posse, Pedreira e Arthur Nogueira.

\subsection{INDICADORES}

Os indicadores que estão sendo levantados os dados são resultado da subdivisão dos temas e todos respeitam os períodos quadrienais (1992; 1996; 2000; 2004; 2008; 2012).

- Saúde: índice de mortalidade Infantil; número de Unidades Básicas de Saúde; número de Hospitais.

- Educação: índice de analfabetismo; número de unidades de escola com educação infantil e educação básica.

- Economia: PIB (per capita); despesas (per capita); receitas (per capita); empregos por área da economia (serviço, indústria, comércio, agropecuária, administração pública).

- Social: evolução populacional; IDHM.

- Uso do Solo: índice de urbanização; saneamento básico; imposto predial e territorial urbano - IPTU; imposto sobre a propriedade territorial rural - ITR.

Todos os indicadores serão relacionados com os mapas políticos verificados - partidário e familiar, a fim de extrair análises que indiquem se a dominância partidária é benéfica para a cidade, assim como a familiar, qualificando ainda, de acordo com os resultados colhidos em cada gestão, em comparação com os dados dos outros municípios, em boa ou má gestão.

As tabelas e gráficos apresentados a seguir, são referentes às análises políticas dos municípios, onde os indicadores ainda seguem em fase de levantamento.

Tabela 1: Partidos eleitos (1988 - 2008). 


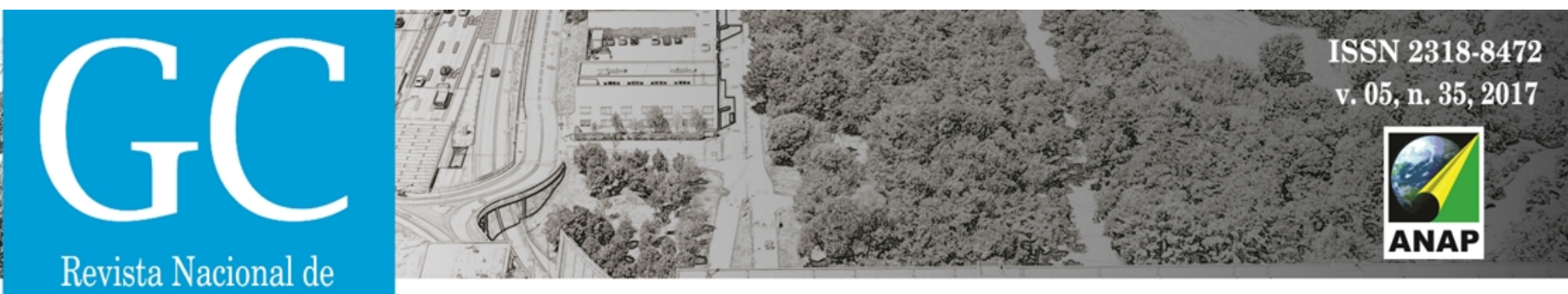

Gerenciamento de Cidades

\begin{tabular}{|c|c|c|c|c|c|c|c|}
\hline MUNICÍPIO & INDICADOR & 1992 & 1996 & 2000 & 2004 & 2008 & 2012 \\
\hline ARTUR NOGUEIRA & \multirow{6}{*}{$\begin{array}{l}\text { PARTIDO } \\
\text { POLÍTICO }\end{array}$} & PL & PMDB & PSDB & PTB & PT & PT \\
\hline PEDREIRA & & PDC & PMDB & PMDB & PFL & PSB & PSB \\
\hline SANTO ANTONIO DE POSSE & & PMDB & PTR & PPB & PMDB & PPS & PPS \\
\hline ENGENHEIRO COELHO & & Não consta* & PMDB & PMDB & PSDB & PMDB & PSDB \\
\hline MORUNGABA & & PFL & PTB & PSD & $\mathrm{PP}$ & PTB & PV \\
\hline HOLAMBRA & & Não consta* & PSD & PSDB & PFL & PFL & PPS \\
\hline
\end{tabular}

Fonte: TRE/TSE/Seade. Elaborado pelo autor.

Através da análise da tabela acima, é possível verificar que em Artur Nogueira, Santo Antônio de Posse e Morungaba houve a eleição de cinco partidos. Em Pedreira e Holambra o número caiu para quatro e em Engenheiro Coelho foram apenas dois os partidos que dividiram o poder executivo local.

$\mathrm{Na}$ tabela foi analisado o período total de 24 anos, ou seja, seis mandatos de quatro anos. Ressalva as exceções de Engenheiro Coelho e Holambra que, emancipados no ano de 1991, tiveram suas primeiras eleições em 1992.

Gráfico 1: Partidos eleitos (1988 - 2008).

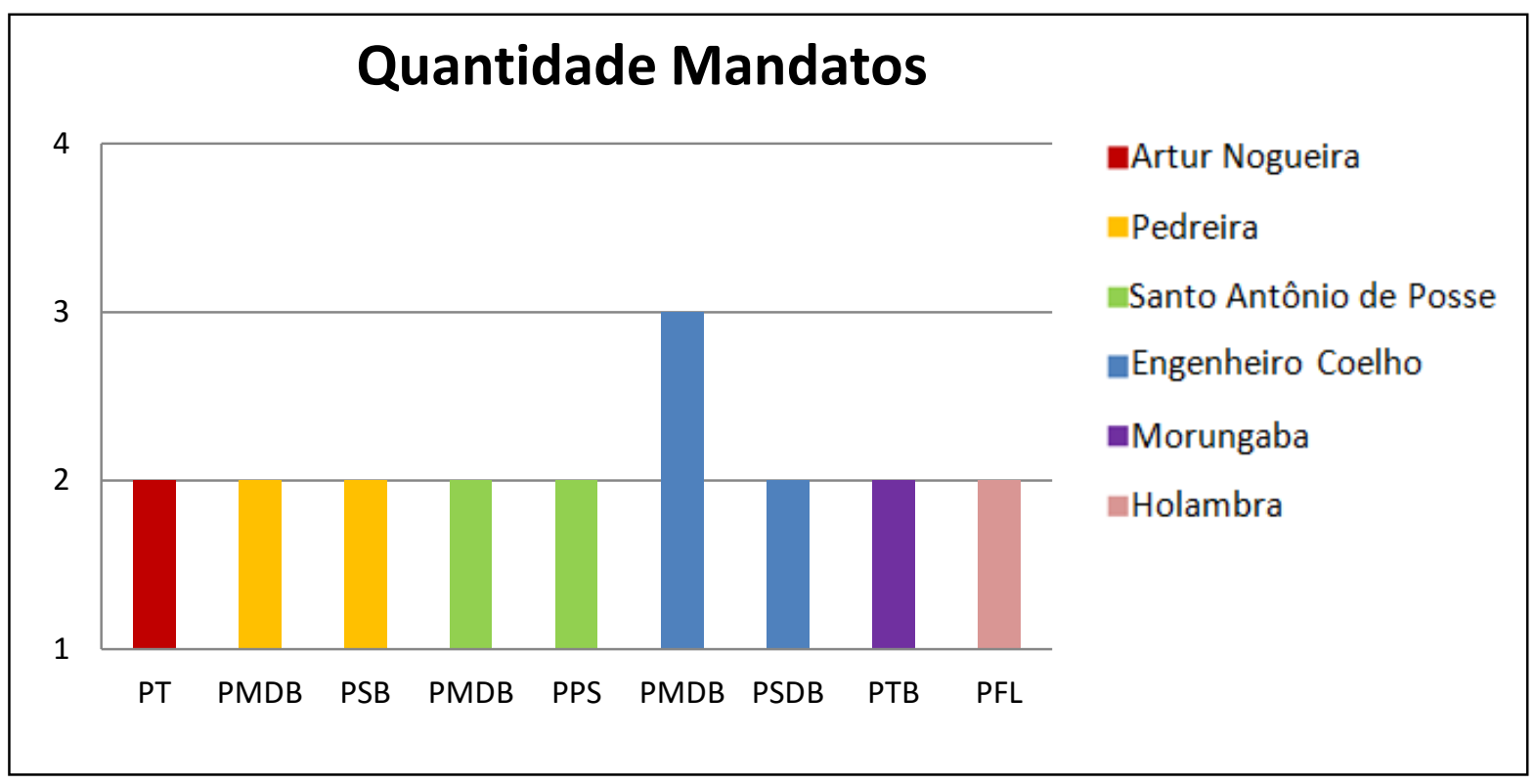

Fonte: TRE/TSE/Seade. Elaborado pelo autor.

Os dados do Gráfico acima contabilizam apenas os partidos reeleitos. Dessa forma, percebe-se que enquanto todos os partidos alternados no poder mantiveram apenas a reeleição nos seis municípios correspondentes da pesquisa, o PMDB foi eleito três vezes no município de 


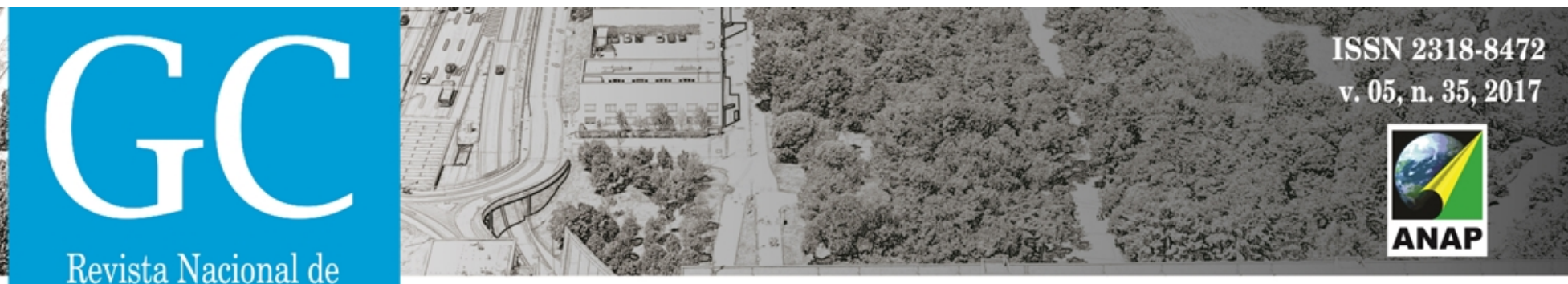

Gerenciamento de Cidades

National Journal of Cities Management

Engenheiro Coelho, ou seja, em 50\% dos mandatos, houve representação política de um mesmo partido e ideologia.

Quadro 1: Prefeitos e vice-prefeitos eleitos (1988 - 2008).

\begin{tabular}{|c|c|c|c|c|c|c|c|}
\hline MUNICÍPIO & INDICADOR & 1992 & 1996 & 2000 & 2004 & 2008 & 2012 \\
\hline ARTUR NOGUEIRA & \multirow{6}{*}{$\begin{array}{l}\text { PREFEITO E VICE- } \\
\text { PREFEITO }\end{array}$} & \begin{tabular}{|l|} 
Ederaldo Rossetti \\
Ademir Favero
\end{tabular} & \begin{tabular}{|l|} 
Claudio Alves \\
Menezes \\
Joaquim Francisco \\
de Santana Filho \\
\end{tabular} & $\begin{array}{l}\text { Nelson Stein } \\
\text { Luiz Faveri }\end{array}$ & $\begin{array}{l}\text { Luiz Faveri } \\
\text { Fátima Ap. de Oliveira }\end{array}$ & $\begin{array}{l}\text { Marcelo Capelini } \\
\text { Claudinei Fernando de } \\
\text { Sá }\end{array}$ & $\begin{array}{l}\text { Marcelo Capelini } \\
\text { Rodolfo Simões Coelho }\end{array}$ \\
\hline PEDREIRA & & \begin{tabular}{|l|} 
Hygino Amadeu \\
Bellix \\
Antonio Ganzarolli \\
Filho \\
\end{tabular} & \begin{tabular}{|l} 
Hamilton \\
Bernardes $\rfloor r$. \\
Antonio Luis \\
Pedroso \\
\end{tabular} & \begin{tabular}{|l} 
Antonio Ganzarolli \\
Filho \\
Maria Elisa Vicente \\
Pintor \\
\end{tabular} & $\begin{array}{l}\text { Jose Carlos Lena } \\
\text { Sérgio Ferrari Rossi }\end{array}$ & \begin{tabular}{|l|} 
Hamilton Bernardes Jr. \\
Antonio Ganzarolli Filho
\end{tabular} & $\begin{array}{l}\text { Hamilton Bernardes Jr. } \\
\text { Antonio Ganzarolli Filho }\end{array}$ \\
\hline $\begin{array}{l}\text { SANTO ANTONIO DE } \\
\text { POSSE }\end{array}$ & & $\begin{array}{l}\text { Valdemar } \\
\text { Vicençotti }\end{array}$ & Adalberto Bergo & Assad Nacle Baracat & \begin{tabular}{|l} 
Antonio de Pádua \\
Ferreira e Silva \\
Antonio Natal Recco
\end{tabular} & $\begin{array}{l}\text { Norberto de Olivério Jr. } \\
\text { Antonio Natal Recco }\end{array}$ & $\begin{array}{l}\text { Norberto de Olivério Jr. } \\
\text { Antonio Natal Recco }\end{array}$ \\
\hline ENGENHEIRO COELHO & & & $\begin{array}{l}\text { Mariano A. Franco } \\
\text { de Oliveira } \\
\end{array}$ & \begin{tabular}{|l} 
José Otavio Scholl \\
José Henrique \\
Fagundes de Gouvea
\end{tabular} & $\begin{array}{l}\text { José Otavio Scholl } \\
\text { José Henrique } \\
\text { Fagundes de Gouvea }\end{array}$ & $\begin{array}{l}\text { Mariano A. Franco de } \\
\text { Oliveira } \\
\text { José F. Ribeiro Mendes }\end{array}$ & \begin{tabular}{|l} 
Rosimeire M. Guidotti \\
Scholl \\
Jose Henrique Fagundes \\
de Gouvea \\
\end{tabular} \\
\hline MORUNGABA & & $\begin{array}{l}\text { Moacyr Tobias } \\
\text { Osvaldo Moraes }\end{array}$ & $\begin{array}{l}\text { Maria Cecília Pretti } \\
\text { Rossi } \\
\text { Onofre da Costa }\end{array}$ & $\begin{array}{l}\text { Lucio Roque Flaibam } \\
\text { Angelina Frare Tobias }\end{array}$ & $\begin{array}{l}\text { Maria Cecília Pretti } \\
\text { Rossi } \\
\text { Onofre da Costa }\end{array}$ & $\begin{array}{l}\text { Luvaldo Andre Flaibam } \\
\text { Jose Roberto Zen }\end{array}$ & $\begin{array}{l}\text { Jose Roberto Zen } \\
\text { Marco A. de Oliveira }\end{array}$ \\
\hline HOLAMBRA & & & \begin{tabular}{|l} 
Celso Capato \\
Petrus \\
Bartholomeus \\
Weel \\
\end{tabular} & $\begin{array}{l}\text { Antonio Marino } \\
\text { Brandão de Almeida } \\
\text { Antonio de Souza }\end{array}$ & \begin{tabular}{|l} 
Celso Capato \\
Jose Benedito de Souza
\end{tabular} & $\begin{array}{l}\text { Celso Capato } \\
\text { Jose Benedito de Souza }\end{array}$ & $\begin{array}{l}\text { Margareth Rose de } \\
\text { Oliveira Groot } \\
\text { Edlson Itamar Picão }\end{array}$ \\
\hline & $\begin{array}{l}\text { PREFEITOS } \\
\text { VICE-PREFEITOS }\end{array}$ & & & & & & \\
\hline
\end{tabular}

Fonte: TRE/TSE/Seade. Elaborado pelo autor.

Acima, a tabela com os prefeitos e vice-prefeitos eleitos levantados até o presente momento, permitindo então que seja verificada a existência de determinados grupos no poder. Ora uma família é eleita através da figura do prefeito, ora ela retorna como vice.

O Gráfico 2 elenca as famílias de destaque, que promovem essa alternância de poder. Novamente, os dados analisados são referidos em seis mandatos. Portanto, observar que em todos os municípios estudados, pelo menos uma família foi eleita três vezes, ou seja, em $50 \%$ das eleições, com destaque para a família Ganzarolli, pertencente ao município de Pedreira, que esteve à frente do governo em quase 70\% das eleições realizadas após a Constituição de 1988, indica que existe sim uma dominância familiar acontecendo nestas cidades. 


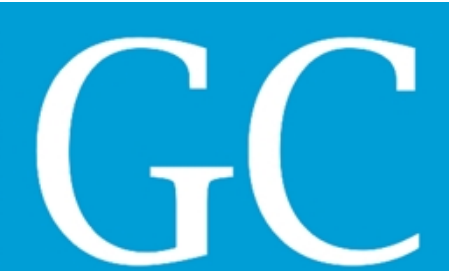

Revista Nacional de

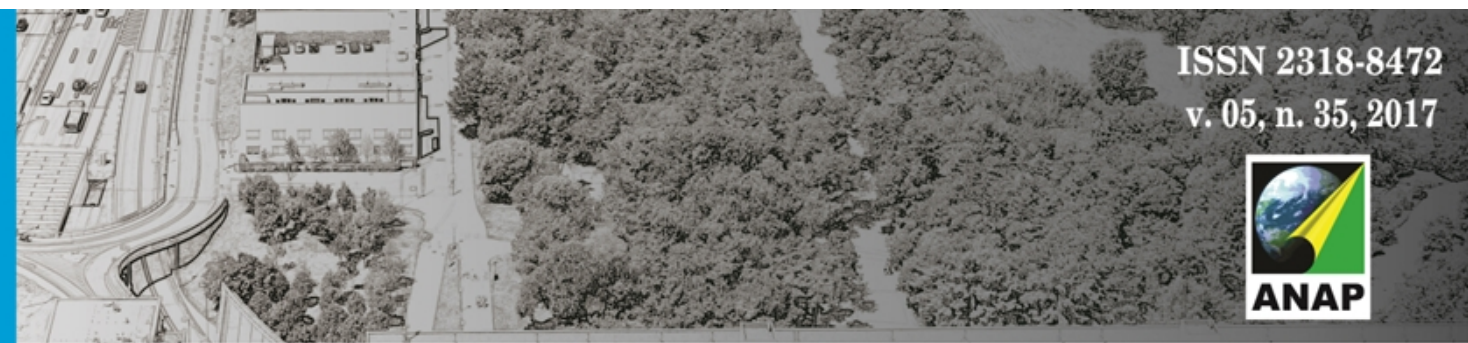

Gráfico 2: Relação de Famílias Eleitas (1988 - 2008).

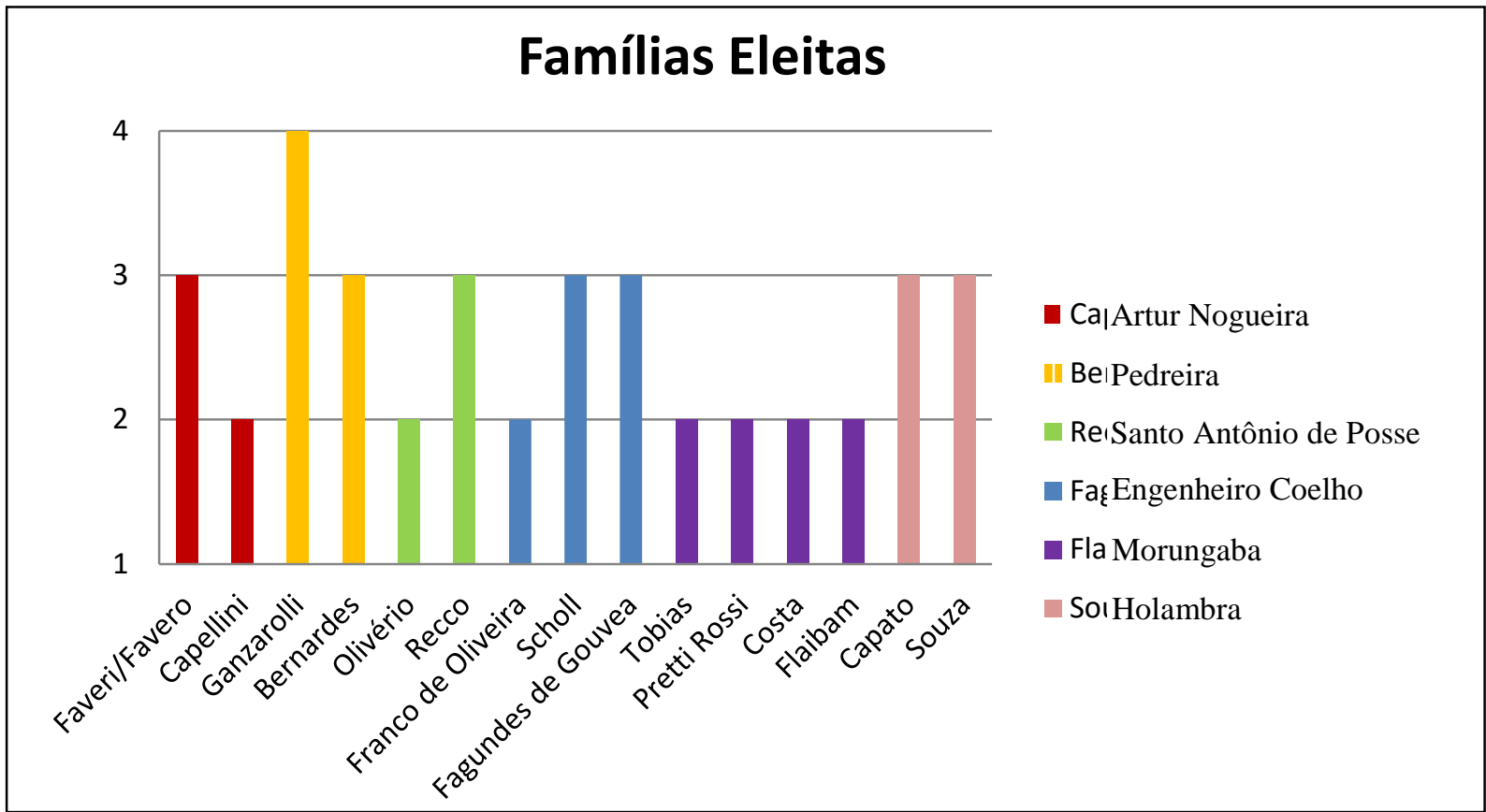

Fonte: TRE/TSE/Seade. Elaborado pelo autor.

Ao comparar os partidos eleitos com as famílias eleitas, através da tabela 1 e tabela 2, tem-se que o número de famílias é maior, concluindo, portanto que, em alguns casos, o prefeito foi reeleito, mas através de outro partido político. Ou seja, a dominância familiar se impôs frente à partidária.

\section{CONCLUSÕES}

Através dos dados apresentados no presente artigo, tem-se uma análise parcial que aponta tendência para um dos cenários levantados na hipótese: a dominância familiar. A partir dessa constatação, será possível verificar os indicadores também elencados no texto, a fim de verificar o impacto que tal configuração política causa em todos os aspectos relacionados à sociedade e interesses coletivos dentro das diferentes gestões de cada município e também, entre municípios. Ainda, a título de comparação, a reeleição partidária - mesmo que em número menos expressivo, bem como a alternância ideológica dos prefeitos eleitos - que trocaram de partido a cada eleição, também seguirão em análise correlacionada com os indicadores municipais estruturados.

Vale ressaltar que os dados que comprovam a dominância familiar corroboram com os dados históricos de formação dos municípios brasileiros, que, conforme expostos, afirmam que a sociedade atual é reflexo e consequência de um processo de segregação espacial herdado desde 


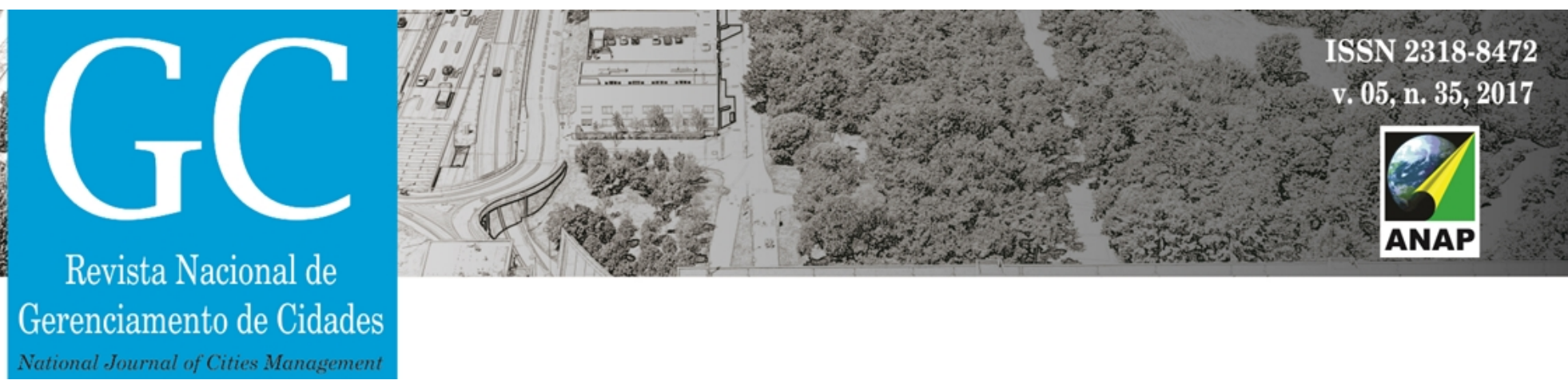

os tempos do Brasil-colônia. Sendo assim, a questão de grupo ou classe dominante irá permanecer presente no decorrer das análises, como embasamento para relacionar os cenários políticos constatados com as ações pretendidas, realizadas ou procrastinadas pelo poder público em relação à sociedade como um todo.

\section{REFERÊNCIAS BIBLIOGRÁFICAS}

Livro:

GOMES, L. G. F. F. Novela e sociedade no Brasil. Niterói: EdUFF, 1988. 137p.

TELLES, P.C.S. Tubulações industriais: materiais, projeto e desenho. 7. ed. Rio de Janeiro: Livros Técnicos e Científicos, 1989. 230p.

CASTRO, Iná Elias de; GOMES, Paulo César da Costa; CORRÊA, Roberto Lobato (Org.). Brasil: questões atuais da reorganização do território. Rio de Janeiro: Bertrand Brasil, 1996. 330p.

Capítulo de Livro:

ROMANO, Giovanni. Imagens da Juventude na era moderna.In: LEVI, G.; SCHMIDT, J. (Org.) História dos jovens 2. São Paulo: Companhia das Letras, 1996. p. 7-16.

PERRONE-MOISÉS, L. Don Juan na literatura de hoje. In: RIBEIRO, R.J. (Org.) A sedução e suas máscaras: ensaios sobre Don Juan. São Paulo: Companhia das Letras, 1988. p.129-141.

Instituição pública:

BRASIL. Ministério das Cidades. Como anda Salvador. Brasília: Ministério das cidades, 2008, 197p.

BAHIA. Governo do Estado; SEPLANTEC. Secretaria de Planejamento e Tecnologia. Inventário de plantas medicinais do Estado da Bahia. Salvador: SEPLANTEC, 1979, 134p.

SALVADOR, Prefeitura da Cidade de; OCEPLAN, Órgão Central de Planejamento. Diagnóstico de circulação e de transportes da cidade de Salvador: PLANDURB. Salvador: Prefeitura Municipal de Salvador, 1975.

INSTITUTO BRASILEIRO DE GEOGRAFIA E ESTATÍSTICA (IBGE). Sidra: Banco de dados. Disponível em: <http://www.sidra.ibge.gov.br>, acesso: 15 jun. 2007.

Periódico:

PÍNTAUDI, S. M. O lugar do supermercado na cidade capitalista. Boletim de Geografia Teorética, Rio Claro, v. 9, n. 17-18, 1984, p. 37-54.

SPOSITO, M. E. B.. A gestão do território e as diferentes escalas de centralidade urbana. Revista Território, Rio de Janeiro, v. 3, p. 27-37, 1998. Disponível em: <http://www.laget.igeo.ufrj.br/territorio/index.htm>, acesso: 20 jun. 2007. 
FRIAS FILHO, O. Peça de Calderón sintetiza teatro barroco. Folha de São Paulo, São Paulo, 23 out. 1991. Caderno 1, p.3.

Tese, dissertação e monografia:

SPOSITO, M. E. B. O chão arranha o céu: a lógica da (re)produção monopolista da cidade, 1991. 383 f. Tese (Doutorado em Geografia Humana)-Faculdade de Filosofia, Letras e Ciências Humanas, Universidade de São Paulo, São Paulo, 1991

ARAÚJO, U. A. M. Máscaras inteiriças Tukúna: possibilidades de estudo de artefatos de museu para conhecimento do universo indígena. 1985. 102f. Dissertação (Mestrado em Ciências Sociais) - Fundação Escola de Sociologia e Política de São Paulo, São Paulo, 1986.

SANTOS, Janio. A produção espacial do comércio e dos serviços na periferia de Salvador. 1999. 140f. Monografia (Bacharelado em Geografia)-Instituto de Geociências. Universidade Federal da Bahia. Salvador, 1999

Anais:

CANÇADO, Agenor Lopes. Toxocomanias de substituição. In: CONGRESSO FARMACÊUTICO E BIOQUÍMICO PAN-AMERICANO, 3. , 1989, São Paulo. Anais... São Paulo: Federação das Associações de Farmacêuticos do Brasil, 1990. p. 259-300.

SILVA, R.N.; OLIVEIRA, R. Os limites pedagógicos do paradigma da qualidade total em educação. In: CONGRESSO DE INICIAÇÃO CIENTÍFICA DA UFPE, 4. , Anais ... Recife: UFPE, 1996. Disponível em: <http://www.propesq.ufpe.br/anais/anais/educ/ce04.htm>. Acesso em: 21 jan. 1997. 